\title{
Uso de tecnologias de informação e comunicação na gestão pública: exemplos no governo federal
}

Ronald da Silva Balbe

\section{Introdução}

As inovações tecnológicas estão alterando os padrões de relacionamento dos governos com os cidadãos. A administração pública contemporânea, de modo voluntário ou reagindo a estímulos, vem se tornando mais sensível a essas mudanças. No entanto, a utilização e a adaptação de técnicas oriundas do setor privado têm sido frequentes em função da dimensão e complexidade do setor público, e soluções inovadoras estão surgindo dentro das próprias organizações públicas.

Essas novas práticas estão associadas em grande medida ao conceito de governo eletrônico, que não pode ficar restrito à mera automação dos escritórios. O mundo contemporâneo exige bem mais dos governos; a cobrança por maior eficiência dos processos, aumento da transparência e maior efetividade das políticas públicas tem sido intensa. Apesar do foco no cidadão, as inovações do setor público não se restringem ao relacionamento do governo com esse público, 
visto que aprimoramentos vêm sendo realizados também na relação do governo com o setor privado e no relacionamento governo com governo.

No Brasil, como no resto do mundo, o governo eletrônico se amplia na segunda metade da década de 1990, envolvendo as mais diversas áreas e indivíduos. A partir dessa data ocorre maior uso de grandes bancos de dados, tanto para acumular registros quanto para gerenciar informações relevantes. Os avanços tecnológicos têm auxiliado também o aprimoramento da tomada de decisão, em especial nos setores que mantêm contato direto com a população, em que a resposta tempestiva é uma questão essencial. Dentro desse contexto, este trabalho tem como objetivo apresentar as recentes inovações em tecnologia da informação e comunicação (TIC) no âmbito da administração pública federal brasileira. $\mathrm{Na}$ sequência desta introdução, a segunda parte discorrerá sobre os aspectos gerais envolvendo governo eletrônico e a evolução recente do e-gov brasileiro.

A terceira parte apresentará cinco experiências inovadoras em TIC, todas premiadas nos concursos anuais Inovação na Gestão Pública Federal, realizados pela Escola Nacional de Administração Pública (ENAP). A escolha dos casos narrados levou em consideração o modelo de análise desenvolvido por Snellen (2002), que agrupa cinco tipos distintos de tecnologia. As experiências inovadoras são: Portal da Transparência da Controladoria-Geral da União (CGU); o Programa Nacional do Livro Didático (PNLD), do Fundo Nacional de Desenvolvimento da Educação (FNDE); o uso dos computadores de mão pelo Instituto Brasileiro de Geografia e Estatística (IBGE); a entrega da Declaração do Imposto de Renda via internet; e a utilização de urnas eletrônicas nas eleições brasileiras.

\section{Elementos contextuais}

A administração pública contemporânea traz como marca as grandes e constantes mudanças, em especial aquelas ocorridas nos últimos trinta anos. Existe na literatura da administração pública - e por que não da sociologia e da ciência política, por serem áreas correlatas ou que sustentam as bases da primeira - certa controvérsia em definir a sociedade em que vivemos. Atualmente existem diversas formas de categorizar a nova realidade que surgiu a partir da revolução das tecnologias de informação.

Giddens (1991), antes de entrar na discussão sobre a denominação ideal, conceitua o elemento central antecedentea modernidade. Para o autor, essa se refere ao estilo, ao costume de vida ou à organização social que surgiram no continente europeu a partir do século XVII e que, posteriormente, se ampliaram para o resto do mundo. Segundo Giddens, sob a ótica das ciências sociais, existe uma estonteante variedade de termos para descrever que estamos no limiar de uma nova era (tal como sociedade da informação, sociedade do consumo, era do conhecimento), dando a entender que estamos chegando ao encerramento de um ciclo (pós-modernidade, sociedade pós-industrial). De acordo com o autor inglês, estaríamos nos deslocando de um sistema baseado na manufatura de bens materiais para outro relacionado com a informação.

Já Castells (2005) afirma primeiramente que já vivemos na sociedade em rede, posto que não se pode alimentar a perspectiva de que somente a atingiremos quando convivermos lado a lado com robôs e muitas máquinas sofisticadas, preconizadas até pouco tempo atrás por futurólogos mais ousados. Contudo, para 
ele, de forma semelhante à sociedade industrial, atualmente convivemos em um ambiente misto, onde nem todas as atividades ou mesmo todos os lugares estão organizados segundo a lógica e a estrutura da sociedade em rede. De fato, o desenvolvimento da sociedade atual tem utilizado como pontos centrais a microeletrônica e a comunicação digitalizada.

Mas a característica abrangente desta sociedade que surge não deve passar a idéia de que existe uma única sociedade em rede. Castells (2005) acredita que da mesma forma como a sociedade industrial não foi a cópia da Inglaterra do século XIX, a sociedade em rede desenvolvida em cada país leva em consideração a cultura, a história, a identidade e o modo de vida da população local. É um erro imaginar que o modelo Silicon Valley se expandirá por todo o globo.

Para Castells e Himanen (2002), o modelo finlandês contrasta com o californiano, posto que está apoiado fortemente no Estado de Bem-estar Social, sinalizando que pode haver pluralidade de modelos sociais e culturais. Como no caso da sociedade industrial, a sociedade em rede partilha traços estruturais comuns (fundamenta-se na geração do conhecimento, em processar a informação); porém, ao mesmo tempo, partindo de diferentes contextos históricos, variando de instituições e alcançando formas distintas de organização social.

A tecnologia no contexto dos movimentos de reforma da administração pública

A evolução da ciência da administração, notadamente a administração pública, sofreu, ao longo do século $\mathrm{XX}$, influências dos fenômenos sociais, políticos, econômicos e tecnológicos. Assim, com o avanço tecnológico no final do século passado, como era esperado, as mudanças e os movimentos de reforma da administração passaram a incorporar as tecnologias de informação e de comunicação.

Os movimentos de reforma da administração pública são divididos, em geral, em três abordagens distintas ${ }^{1}$. A primeira diz respeito à visão tradicional da

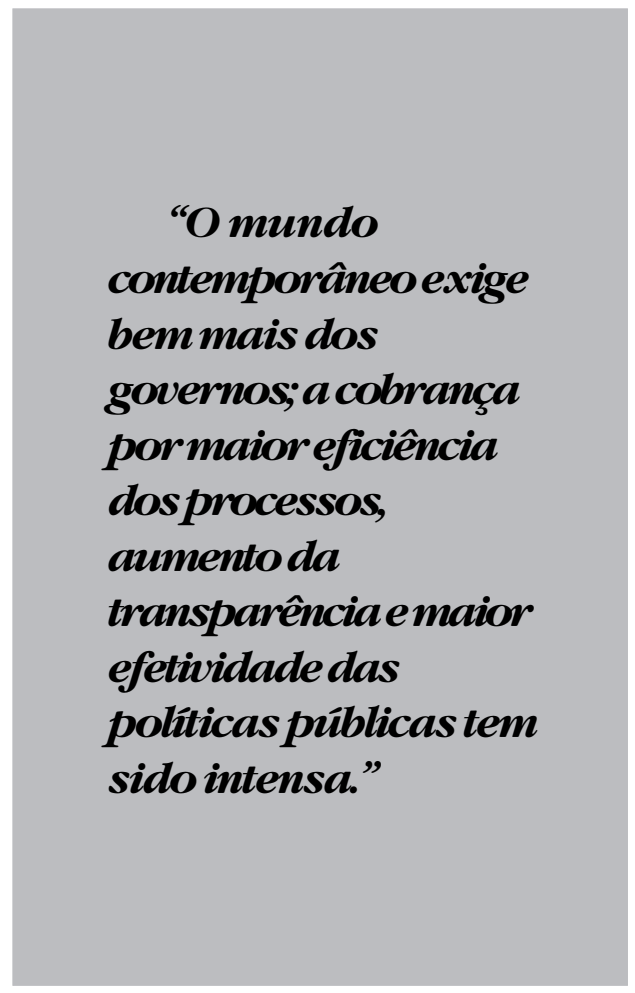

administração, ancorada na perspectiva burocrática, vinculada à escola weberiana, a qual adotou dentre seus princípios o respeito à hierarquia e ao cumprimento das normas. A segunda abordagem, de caráter gerencial, surgida entre as décadas de 1970 e 1980, ficou conhecida como Nova Gestão Pública (NGP). Ainda que os princípios e as ferramentas relacionados a 
esta corrente da administração pública já estejam em uso desde a década de 1980, não existe consenso, conforme anota Giauque (2003), quanto à definição precisa do que exatamente representa NGP. O mencionado autor aponta como os principais objetivos da NGP: aumento dos serviços de atendimento ao público; modernização dos processos de produção, mediante mais flexibilidade e maior adaptação na organização dos serviços; definição mais clara dos objetivos a serem atingidos por meio de contratos; aprimoramento do acesso da população aos resultados; claro desejo de incrementar a produtividade das organizações.

A terceira abordagem, até por conta da falta de distanciamento histórico, tem sido objeto de controvérsia. Há determinados autores que identificam o movimento Novo Serviço Público (NSP) como o fenômeno que melhor explica a etapa posterior à Nova Gestão Pública (Denhardt e Denhardt, 2003). A principal proposta do NSP é a recuperação dos valores democráticos e sociais, mediante o aumento da participação da sociedade nas decisões governamentais. De forma resumida, o movimento do Novo Serviço Público não despreza os avanços obtidos com o gerencialismo, ao mesmo tempo em que enfatiza a importância de valorizar o foco no cidadão habitante em um Estado democrático de direito. Assim, tenta preservar, em parte, os valores da administração pública clássica.

Já outros autores, mais sensíveis aos impactos provocados pelas mudanças tecnológicas, apesar de não colocarem o e-governement como uma etapa posterior à Nova Gestão Pública, identificam-no como um fenômeno relevante que marca a administração pública contemporânea ${ }^{2}$. O trabalho de Gil-Garcia e Luna-Reyes
(2008) apresenta uma revisão da literatura a respeito do tema, destacando os conceitos, aplicações e estágios do governo eletrônico na visão de diversos autores. Em essência, o detalhamento de diferentes abordagens demonstra a magnitude da utilização das tecnologias de informação e comunicação, corroborando a tese de que um novo movimento de reforma da administração pública está em desenvolvimento.

\section{O governo eletrônico}

De maneira geral, governo eletrônico significa a utilização das tecnologias de informação e comunicação no âmbito da administração pública. Braga et al. (2008) apresenta conceitos de e-gov utilizados pelas tradicionais agências internacionais. Os autores informam que, para as Nações Unidas, e-government inclui virtualmente todas as aplicações e plataformas de TIC usadas no setor público. A Organização para a Cooperação e Desenvolvimento Econômico (OCDE) define o uso das TICs, em particular a internet, como ferramenta para levar a um melhor governo. Já para a Comunidade Européia, e-gov relaciona-se ao uso das TICs na administração pública combinado com mudança organizacional e novas práticas ${ }^{3}$.

Essa última conceituação está em consonância com o entendimento de Abranson e Means (2001), citados por Diniz et al. (2009). Os autores afirmam que e-gov não se restringe a mera automação, mas envolve uma mudança na maneira como o governo, pelo uso das TICs, atinge os seus objetivos, incluindo, assim, melhoria de processos, aumento da eficiência, melhor governança, elaboração e monitoramento de políticas públicas, aumento da transparência. 
Para tratar do tema, Gil-Garcia e LunaReyes (2008) estruturam a concepção de e-government em três diferentes maneiras, quais sejam: a definição concreta; suas diferentes aplicações; e as diversas etapas do processo evolutivo do e-gov. Quanto à primeira abordagem - conceitual, apoiando-se em Grönlund e Horan (2004), Gil-Garcia e Luna-Reyes mencionam quatro definições distintas: a primeira coloca governo eletrônico como sendo a provisão de informações, serviços e outras atividades baseados na internet; a segunda descreve e-gov como sendo o uso da tecnologia da informação e comunicação no governo; a terceira destaca o redesenho das ações governamentais após a utilização dos recursos da TIC; a quarta trata da criação do "better government" mediante os processos internos e os relacionamentos com a sociedade civil.

$\mathrm{Na}$ segunda forma de tratar e-government - à luz de suas aplicações os autores apresentam o mapeamento adaptado da obra de Rosenbloom (1998), conforme Quadro 1. As três abordagens da administração pública (administrativa, política e legal) são trabalhadas em quatro categorias e onze elementos distintos.
Ainda sobre as aplicações de TIC, vale mencionar a classificação que Gil-Garcia e Luna-Reyes (2008) fazem do relacionamento do governo com os cidadãos e outros parceiros: relacionamento governo com o cidadão (em inglês government to citizen, que dá origem à sigla G2C); relacionamento governo com o setor privado (government to business - G2B); e relacionamento do governo com o governo (government to government - G2G).

$\mathrm{Na}$ terceira abordagem - os estágios do e-gov-, Gil-Garcia e Luna-Reyes (2008) mostram os quatro estágios do desenvolvimento do governo eletrônico. O primeiro diz respeito à catalogação, operacionalizada por meio da classificação das informações, e a respectiva apresentação em páginas eletrônicas. O segundo estágio é a transação, quando organizações públicas e cidadãos interagem via sítios eletrônicos. O terceiro estágio refere-se à integração vertical, que consiste na reunião física e virtual de diferentes órgãos e fases do processo de gestão pública. $\mathrm{O}$ quarto e último estágio está vinculado à transformação do processo de trabalho com a quebra das barreiras, exigindo, portanto, uma complexa transformação.

\section{Quadro 1: Mapeamento das aplicações de e-government}

\begin{tabular}{l|l|l}
\hline $\begin{array}{l}\text { Abordagens de } \\
\text { Administração } \\
\text { Pública }\end{array}$ & Categorias de e-gov & Elementos de e-gov \\
\hline Administrativa & e-serviço & \\
& e-administração & $\begin{array}{l}\text { e-serviço, e-comércio } \\
\text { e-administração, e-recursos } \\
\text { humanos, e-licitações }\end{array}$ \\
\hline Política & e-democracia & $\begin{array}{l}\text { e-democracia, e-participação, } \\
\text { e-voto, e-transparência }\end{array}$ \\
\hline Legal & e-política pública & e-política pública, e-governance \\
\hline
\end{tabular}

Fonte: GiL-Garcia E Luna-Reyes (2008) 


\section{O governo eletrônico no Brasil}

Acompanhando a tendência mundial, o governo eletrônico no Brasil ganha relevância na segunda metade da década de 1990. Diniz et al. (2009), apoiados no trabalho de Reinhard e Dias (2005), identificam quatro períodos do uso de TIC no setor público brasileiro: pioneirismo (1950 a 1965); centralização (1965 até o final da década de 1970); terceirização (década de 1980); o governo eletrônico propriamente dito (a partir de 1990).

No período mais recente, cabe destacar os seguintes fatos: os preparativos para o bug do milênio, a criação do Comitê Executivo de Governo Eletrônico, a transição entre o governo do presidente Fernando Henrique Cardoso e o governo do presidente Luiz Inácio Lula da Silva, a interoperabilidade de governo eletrônico e o esforço para a ampliação da inclusão digital.

O "bug do milênio" criou as condições para acirrar o debate a respeito do governo eletrônico, levando-o para a agenda de políticas públicas. Segundo Kingdon (2006), é fundamental distinguir situação e problema para tornar claro o momento em que o assunto vira prioridade na agenda nacional. Para o autor, toleramos vários tipos de situações durante algum tempo, sem que essas sejam colocadas na agenda. Contudo, quando os mesmos eventos passam a ser encarados como problemas, ou seja, quando é preciso fazer algo para mudar, as chances de o assunto se tornar prioridade aumentam. Assim, o bug pode ter sido o grande responsável por levar o tema governo eletrônico para a agenda e, dessa forma, dar origem a diversas medidas de modernização da máquina pública.

No ano 2000 foi criado o Comitê Executivo de Governo Eletrônico, que tinha o Ministério do Planejamento nas funções de Secretaria-Executiva e o chefe da Casa Civil como o principal dirigente. Em 2001 aconteceu o lançamento da Política de Governo Eletrônico no Brasil, com as seguintes linhas de ação: oferta na internet de todos os serviços prestados ao cidadão; ampliação do acesso a informações, redes e bancos de dados; promoção da convergência entre os sistemas de informações; implantação de infraestrutura avançada de comunicações e serviços; utilização do poder de compra do governo para obtenção de custos menores.

Sobre a infraestrutura, cabe destacar que em 2001 foi instituída a Infraestrutura de Chaves Públicas Brasileira (ICP-Brasil) com a finalidade de garantir autenticidade, integridade e validade jurídica de documentos em formato eletrônico. Desde então, diversos serviços passaram a operar com a certificação digital - dentre os quais, a partir do levantamento de Braga (2008), é possível destacar: Sistema de Pagamento Brasileiro (responsável pelo gerenciamento do processo de compensação e liquidação de pagamentos das instituições financeiras); registro de operações e prestações de impostos federais pela internet; portal de compras e pregões eletrônicos; internet banking.

Outro fato digno de nota foi o processo de esfriamento do debate em torno do tema governo eletrônico, ainda que isto não represente a retirada completa do assunto da pauta. Na verdade, ainda em 2001, outro tema passou a dominar as atenções, sobretudo do ministro da Casa Civil, até então um dos personagens mais importantes para o boom do governo eletrônico. A crise energética brasileira, popularmente conhecida como "apagão", dominou a cena no período. Outra contribuição relevante foi o fortalecimento do candidato de oposição 
(com a subsequente vitória de Lula), que acabou desmotivando as equipes daquela gestão para o trabalho de longo prazo. O processo de transição afetou a área dentro do governo, que somente foi mobilizada novamente a partir de meados de 2004, com destaque para a criação do Departamento de Governo Eletrônico, dentro da Secretaria de Logística e Tecnologia da Informação/Ministério do Planejamento (Diniz et al., 2009).

Em 2005, foram instituídos os Padrões de Interoperabilidade de Governo Eletrônico (e-PING), os quais têm permitido aprimorar o fluxo de informação entre o governo e a sociedade. De acordo com a Secretaria de Logística e Tecnologia da Informação (2009), essa arquitetura possibilita que mesmo sistemas de informação com arquiteturas diferentes e desenvolvidos em épocas distintas possam gerar e trocar informações em tempo real. Um exemplo de sucesso foi o Sistema Infoseg, que possibilitou ao Ministério da Justiça promover a integração das bases criminais dos estados brasileiros.

A inclusão digital e a compreensão de que o cidadão é o grande consumidor dos serviços eletrônicos eventualmente oferecidos pelo governo é outro tópico importante dentro da evolução do e-gov. Os dados disponíveis sobre o tema apresentam um quadro muito similar à situação socioeconômica da população brasileira ${ }^{4}$. De 2005 para 2008, o total de internautas na área urbana subiu de 36,6 milhões para 55,5 milhões (BArbosa et al., 2009), o que em termos relativos representa aproximadamente $29 \%$ de todos os brasileiros. Contudo, essa fração é inferior às médias latino-americana/caribenha, européia e norte-americana, de 30\%, 52\% e 74\%, respectivamente (Internet World Stats, 2009). Na mesma linha, Waiselfisz (2007) salienta ainda que de acordo com os dados da Pesquisa Nacional por Amostra de Domicílios (PNAD)/IBGE de 2005, o uso da internet, segundo a renda per capita, por parte dos $40 \%$ mais pobres é de apenas $5,7 \%$, enquanto no total dos $10 \%$ mais ricos, é de $58,7 \%$.

Desse modo, o conhecido quadro de desigualdades se repete também quando se analisa a inclusão digital. Assumpção (2009) afirma que o fenômeno das desigualdades

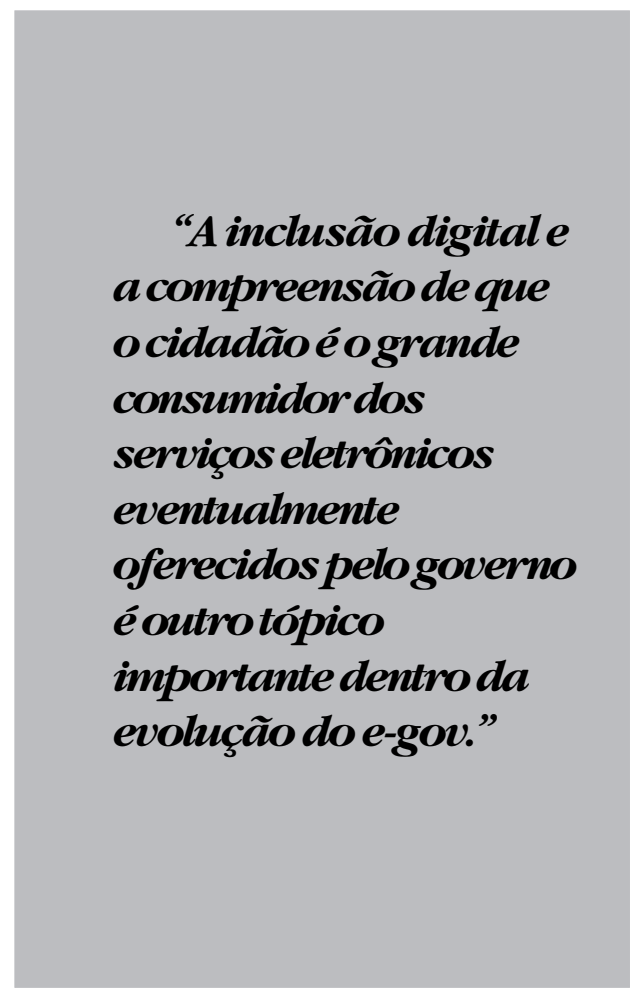

encontrou na exclusão digital um vigoroso aliado. Para o autor, o vínculo entre inclusão digital e governo eletrônico deve ser claro e forte, pois, do contrário, contribuirá ativamente para que apenas a parte privilegiada da sociedade tenha acesso aos serviços públicos na internet.

De acordo com o Observatório de Políticas Públicas de Inclusão, elaborado 
pelo Instituto Brasileiro de Informação em Ciência e Tecnologia (IBICT), existem 108 programas de inclusão digital, atuando em quase 3 mil municípios, sendo que $60 \%$ dos programas contam com financiamento federal direto ou indireto (WAISELFISZ, 2007). Desse conjunto de programas, cabe destaque, pela magnitude e relevância, ao Programa Nacional de Informática na Educação (Proinfo/MEC); ao Governo Eletrônico Serviço de Atendimento ao Cidadão (Gesac), do Ministério das Comunicações; aos Centros de Inclusão Digital do Ministério da Ciência e Tecnologia (MCT) e ao Computador para todos, projeto compartilhado da Presidência, Ministério do Desenvolvimento, Indústria e Comércio (MDIC) e MCT.

Contudo, a oferta de equipamentos de TIC não resolve o problema da exclusão. Mattos e Chagas (2008) entendem ser necessária a definição de um conjunto de indicadores que compare a vida das pessoas antes e depois de terem participado de programas de inclusão digital. A proposta dos autores pressupõe a medição, dentre outros aspectos, da inserção no mercado de trabalho, da facilitação das tarefas cotidianas e da melhoria do relacionamento dos indivíduos com os poderes públicos.

Tendo esse histórico como pano de fundo, a seção seguinte buscará aprofundar a demonstração de cinco inovações no uso de tecnologias de informação no âmbito do governo eletrônico brasileiro.

\section{Cinco experiências de TIC na gestão pública federal}

A partir do levantamento bibliográfico, foram identificadas diversas tipologias e classificações para descrever as tecnologias da informação e comunicação, acentuando as características mais relevantes e as fases de política pública em que essas TICs se encontram inseridas, dentre outros aspectos. Aquela que pareceu mais adequada para a finalidade do presente trabalho consta do ensaio de Snellen (2002). $O$ autor propõe agrupar sistemas de tecnologia da informação, de acordo com os seguintes blocos: tecnologia de banco de dados; tecnologia de suporte à decisão; tecnologias de comunicação e trabalho em grupo; tecnologia de rastreamento e identificação pessoal; e automação de escritório e tecnologias multimídia.

Após agrupar os tipos de tecnologia, Snellen (2002) descreve experiências holandesas. De forma semelhante, esta seção apresenta casos de sucesso no Brasil para cada grupo de tecnologia proposto pelo autor, tomando como referência os concursos anuais de Inovação na Gestão Pública Federal, realizados pela Escola Nacional de Administração Pública. Cabe comentar, contudo, que para efeito de viabilizar a narrativa, nem sempre as experiências inovadoras utilizam um único grupo de tecnologia; ao contrário, fazem uso de mais de um tipo das tecnologias mencionadas. Desse modo, a opção foi identificar a tecnologia empregada com maior relevância.

\section{Tecnologia de banco de dados}

O primeiro bloco trata da tecnologia de banco de dados, sendo este subdividido em três sistemas de informação distintos. $\mathrm{O}$ primeiro - sistemas de registros de objeto é marcado pela acumulação de dados sobre entidades e a população de uma maneira geral. A principal utilidade desses sistemas é permitir a troca e a acumulação de informações entre as burocracias e os cidadãos. O segundo tipo - sistemas de depósito e gerenciamento de informações - têm sido 
aproveitados nas diversas áreas da administração pública, como, por exemplo, na seguridade social, saúde, policiamento, tráfego e transporte. $\mathrm{O}$ terceiro - sistemas de controle de desempenho e monitoramento dos gastos financeiros e recursos humanos e materiais - é gerido pela administração pública com vistas a aumentar o papel da transparência e da accountability governamental das instituições públicas, organizações privadas e parceiros da sociedade civil, notadamente as organizações não governamentais.

O Portal da Transparência, administrado pela Controladoria-Geral da União (CGU), foi criado em novembro de 2004, tendo como objetivo a ampliação da transparência dos gastos públicos no âmbito do governo federal. Diante da maior visibilidade dos gastos, o órgão pretendeu também estimular a participação e o controle social. A experiência foi premiada em diversos fóruns, cabendo destacar dois: em termos internacionais, o Portal foi reconhecido como uma experiência exemplar pelas Nações Unidas, na Conferência dos Estados Partes da Convenção da ONU contra a Corrupção, na Indonésia, em novembro de 2008; no nível nacional, em 2007, ficou em 5을 lugar no $12^{\circ}$ Concurso Inovação na Gestão Pública Federal, conduzido pela ENAP.

$O$ volume de dados supera os $780 \mathrm{mil}$ registros, representando um total de recursos superior a $\mathrm{R} \$ 5,4$ trilhões ${ }^{5}$. O Portal permite a realização de consultas aos dados sobre a execução financeira de todos os programas e ações do governo federal, em linguagem simples, navegação amigável e sem necessidade de senhas. Sendo assim, entende-se que o Portal pode ser considerado um caso bemsucedido na utilização da tecnologia de banco de dados nos termos propostos por Snellen (2002), sobretudo porque tem como finalidade precípua, inclusive no próprio nome, a transparência.

O Portal da Transparência vem sendo alimentado por diversas fontes de dados, como a execução financeira do Sistema Integrado de Administração Financeira do Governo Federal (Siafi), os dados do Fundo Nacional de Saúde, da Caixa Econômica Federal, do Banco do Brasil. Atualmente, o sistema apresenta cinco tipos de consultas: despesas (aplicações diretas, transferências de recursos aos estados, municípios, Distrito Federal, às organizações não governamentais ou diretamente ao cidadão); receitas; convênios; Cadastro Nacional de Empresas Inidôneas e Suspensas (CEIS) e a pesquisa sobre servidores públicos ${ }^{6}$ (CGU, 2010).

\section{Tecnologia de suporte à decisão}

O segundo bloco - tecnologia de suporte à decisão - serve para auxiliar o processo de formulação das decisões, as quais podem ser simples ou complexas, exigindo a participação de experts. Atualmente, esses sistemas de suporte à decisão estão se aprimorando, e já é possível notar que estão migrando do back office para o front office, especialmente nos setores onde a administração pública tem grande contato com os cidadãos, como departamentos de polícia, bombeiros, categorias que pertencem ao conjunto de servidores públicos que formam a street-level bureaucracy.

Como exemplo de experiência brasileira que tem feito uso de novas tecnologias para auxiliar na tomada de decisão, foi escolhido o Programa Nacional do Livro Didático, em função de sua dimensão e sua articulação com diversos atores. Este é o mais antigo dos programas voltados à distribuição de obras didáticas aos estudantes da rede pública de ensino 
brasileira e iniciou-se, com outra denominação, em 1929. Desde então, a iniciativa recebeu diversos aperfeiçoamentos. Em 2006 e 2007, foram investidos, respectivamente, $\mathrm{R} \$ 563,7$ milhões e R\$ 661 milhões (FNDE, 2009).

Para o ensino fundamental, com $150 \mathrm{mil}$ escolas e 30 milhões de alunos, são distribuídos 120 milhões de livros. Para o ensino médio, com 17 mil escolas e 7 milhões de alunos, são distribuídos 18 milhões de livros (SCHWARTZ, 2009). O funcionamento do programa prevê 13 etapas, das quais se destacam (FNDE, 2009):

- Inscrição das editoras: após a publicação do edital, as empresas detentoras de direitos autorais apresentam seus produtos;

- Guia do livro: o guia do livro didático é apresentado na internet, com a relação dos livros escolhidos, após a triagem física e técnica realizada pelos órgãos competentes;

- Escolha e pedido: diretores e professores analisam e escolhem as obras que serão utilizadas. A partir de 2009 a escolha ocorreria somente via internet. Até o ano anterior, a internet era opcional (NASCIMENTO, 2009);

- Aquisição: os dados são compilados e o FNDE inicia o processo de negociação com as editoras para a aquisição, realizada por inexigibilidade de licitação, prevista na Lei 8.666/93;

- Produção: o FNDE firma o contrato e informa os quantitativos e as localidades de entrega para as editoras;

- Distribuição: a distribuição dos livros é feita diretamente pelas editoras às escolas, por meio de um contrato entre o FNDE e a Empresa Brasileira de Correios e Telégrafos (ECT);

- Recebimento: os livros chegam às escolas entre outubro e o início do ano letivo.

Sob a ótica da tecnologia que dá suporte à tomada de decisão, a manifestação dos professores pode ser considerada uma iniciativa de destaque, dado que administrar a escolha de quase dois milhões de pessoas não se trata de tarefa trivial. Ademais, em função da necessidade de remanejamento de livros entre escolas e prefeituras, o FNDE desenvolveu o Sistema de Controle de Remanejamento e Reserva Técnica (Siscort), com o qual as redes de escolas públicas podem verificar a disponibilidade de livros nas unidades educacionais mais próximas e registrar possíveis sobras em sua instituição. Apesar da projeção estatística feita pelo Instituto Nacional de Estudos e Pesquisas Educacionais Anísio Teixeira (Inep), pode haver diferença entre o alunado estimado e as matrículas efetivamente realizadas, ocasionando falta ou sobra de obras em determinadas localidades. Assim, esse instrumento também pode ser apontado como mais uma iniciativa baseada em tecnologia da informação, sobretudo a partir de 2009, quando a participação dos professores somente será possível pela internet.

Sob o ponto de vista de logística e distribuição, a atividade vem se desenvolvendo desde 1994, em parceria entre o FNDE e a ECT. Antes dessa reunião de esforços, apenas $25 \%$ dos livros chegavam às escolas antes do início do período letivo. Além do prêmio "Destaque de Gestão Empreendedora" entre as ações premiadas no 7 ํㅡㄴ Concurso Inovação na Gestão Pública Federal, em 2002, o Programa também ficou em primeiro lugar no World Mail Awards, de 2002, mais importante prêmio para empresas postais no mundo (SiLVA, 2002).

\section{Tecnologias de comunicação e trabalho em grupo}

O terceiro bloco - tecnologias de comunicação e trabalho em grupo - é o 
responsável por adicionar a dimensão comunicação na informação tecnológica. Assim, tempo e espaço perderam um pouco do significado que até então possuíam. Alguns exemplos desse tipo de tecnologia são transferência e compartilhamento de arquivos, envio e recebimento de e-mails, salas de bate-papo (chatting) e videoconferência, entre outros.

A utilização de computadores de mão (PDA - Personal Digital Assistant) durante a contagem populacional e o censo agropecuário pelo IBGE, em 2007, pode ser considerada uma das mais bemsucedidas iniciativas de comunicação e trabalho em grupo, tendo em vista a troca de informações e a supervisão do trabalho de 82 mil recenseadores, espalhados em 8,5 milhões de quilômetros quadrados do território brasileiro. A experiência também foi premiada em $1^{\circ}$ lugar no $12^{\circ}$ Concurso Inovação na Gestão Pública Federal (2007), organizado pela ENAP.

A realização do censo com intenso uso de tecnologia contrasta com a origem da atividade há mais de 2.000 anos na China, passando pelo Império Romano ${ }^{7}$. No Brasil, o primeiro censo foi realizado em 1872 antes, portanto, da criação do IBGE, em 1936, quando o processo de contagem ganhou organização e eficiência (IBGE, 2007).

De acordo com Mariano (2007), o projeto foi uma inovação mundial, posto que nenhum país com dimensões similares realizou tal tarefa. Os Estados Unidos estão se preparando para adotar o procedimento. $\mathrm{Na}$ prática, a ação dispensa questionários em papel, substituídos por perguntas na tela do PDA, equipado com GPS ${ }^{8}$. A agilidade do mecanismo (tanto hardware quanto software) permite validar informações coletadas, ao se efetuar a correção de dados inconsistentes e a detecção de erros durante as entrevistas, o que somente ocorria muitos dias depois. Ademais, com a tecnologia de transmissão de dados sem fio, a coleta de dados fica mais confiável e eficiente.

A instituição já vinha progredindo paulatinamente na absorção das novas tecnologias. No Censo de 1991 ocorreu a implantação do modelo descentralizado com minicomputadores nas unidades estaduais do IBGE. Na Contagem de

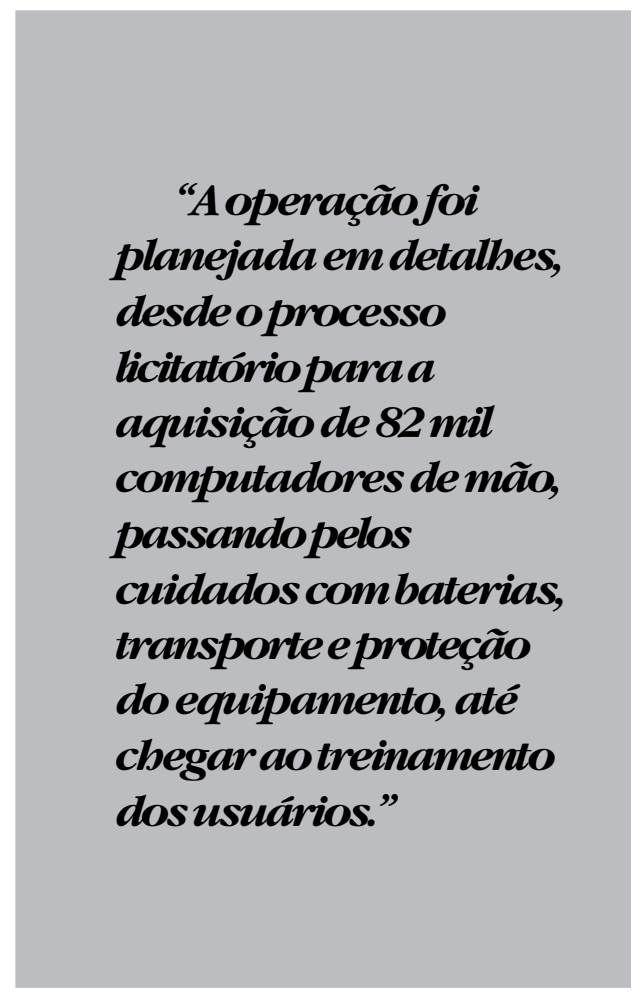

População de 1996, foi a vez de se utilizar leitoras de marcas. No Censo 2000, o Instituto utilizou escâneres com reconhecimento de código de barras e marcas (OMR), caracteres impressos (OCR) e manuscritos (ICR) sobre a imagem dos questionários. Antes da adoção da nova tecnologia dos computadores de mão, os censos demoravam mais de sete meses. 
A despeito das inovações anteriores, o paradigma do questionário em papel não tinha sido quebrado. Assim, a experiência em 2007 foi um grande salto. A operação foi planejada em detalhes, desde o processo licitatório para a aquisição de 82 mil computadores de mão, passando pelos cuidados com baterias, transporte e proteção do equipamento, até chegar ao treinamento dos usuários. As transmissões também exigiram preparação eficiente, tanto que o IBGE equipou 532 agências permanentes em municípios e cerca de 580 locais em outros órgãos públicos com computadores e acesso à internet em banda larga. Nas localidades mais afastadas dos grandes centros (cerca de 4.400), as transferências dos dados foram feitas à central no Rio de Janeiro por linha telefônica fixa, via modem com tecnologia bluetooth entre este e o PDA (Mariano, 2007). O investimento total com as inovações tecnológicas atingiu cerca de $\mathrm{R} \$ 115$ milhões, dos quais $\mathrm{R} \$ 88$ milhões foram destinados à compra dos aparelhos?.

Em resumo, a iniciativa teve como objetivo garantir o melhor funcionamento dos equipamentos em campo, a fim de atingir um maior grau de segurança sobre os dados e melhor supervisão do processo de coleta com possibilidade de correções imediatas. Os principais resultados, conforme anota Mariano (2007), foram a disponibilização dos dados para análise ainda no tempo de levantamentos; georreferenciamento dos estabelecimentos agropecuários; georreferenciamento dos setores de coleta, atendendo ao cadastro de endereços; crítica qualitativa e quantitativa durante a entrevista. $O$ autor apresenta também os fatores críticos de sucesso: suporte de fornecedores de soluções de hardware e software envolvidos; engajamento do grupo de trabalho e o espírito corporativo de seus técnicos.

\section{Tecnologia de rastreamento e identificação pessoal}

O quarto bloco - tecnologia de rastreamento e identificação pessoal - tem crescido muito nos últimos anos, a ponto de influenciar fortemente a formulação e execução das políticas públicas. Atualmente, por meio dos smart cards e outros mecanismos de identificação, é possível rastrear indivíduos, veículos e cargas, facilitando a administração de presídios, estradas e armazéns.

O Receitanet é o sistema utilizado pela Secretaria da Receita Federal, do Ministério da Fazenda brasileiro, para permitir a entrega da Declaração do Imposto do Imposto de Renda via internet. Ao transmitir a declaração, o Receitanet imediatamente valida diversas informações e simultaneamente realiza o processamento, a auditoria, o monitoramento dos dados e a geração de estatísticas. Dessa forma, reduz o tempo e o custo de processamento. Atualmente, todas as declarações são encaminhadas via internet, sendo que, em 2009, mais de 25 milhões de contribuintes utilizaram o sistema (SRF, 2009a).

Em termos de segurança, o sistema utiliza técnicas de compressão e criptografia dos dados, garantindo a confiabilidade na transmissão. Outra característica é a simplicidade: o sistema foi desenvolvido em Java, de acordo com as diretrizes do governo federal para o uso do software livre. Antes de enviar a declaração, o contribuinte é avisado caso exista ainda alguma pendência. Para Nazareno et al. (2007), a eficiência do Receitanet propiciou a rápida adaptação do contribuinte ao mundo digital. 
O mecanismo recebeu diversos prêmios pelo seu pioneirismo, inovação e qualidade, de forma que associações de classes, órgãos públicos e empresas privadas nacionais e internacionais conferiram vários prêmios ao sistema e ao sítio da SRF, dos quais se destacam: $10^{\circ}$ Concurso Inovação na Gestão Pública Federal, promovido pela ENAP em 2006; o e-Government em 2003 - evento a cargo do Word Summit Award (WSA) - e o e-Government Label, conferido pela Comunidade Econômica Européia em 2001. Conforme a SRF (2009b), com essa premiação, obtida ao lado do Sistema Comprasnet (outra iniciativa brasileira que utiliza intensivamente a internet), o Brasil entrou no grupo dos 20 países que já desenvolvem práticas eficientes de governança eletrônica, ao lado de Áustria, Bélgica, Dinamarca, Estônia, Finlândia, França, Alemanha, Grécia, Islândia, Irlanda, Itália, Noruega, Suécia, Portugal, Romênia, Reino Unido, Espanha, Holanda e Estados Unidos.

Como mais uma novidade, a SRF desenvolveu o e-CPF e o e-CNPJ (respectivamente, Cadastro de Pessoa Física e Cadastro Nacional de Pessoa Jurídica), instrumentos por meio dos quais o órgão espera garantir a autenticidade dos remetentes e destinatários de documentos e dados que trafegam pela internet, assegurando sua inviolabilidade. Em fase de implantação, o e-CPF é baseado nas especificações da ICP-Brasil. Pelo menos por enquanto, a novidade custa um valor considerável ${ }^{10}$ para o contribuinte (NAZARENo et al., 2007).

\section{Automação de escritório e tecnologias multimídia}

O quinto e último bloco - automação de escritório e tecnologias multimídia - tem contribuído para as melhorias de processo no âmbito da administração pública mediante a disponibilização de recursos tecnológicos capazes de permitir a revisão e o aprimoramento de determinadas etapas do processo de execução das políticas públicas.

A efetiva utilização do processamento eletrônico de dados para fins de serviços eleitorais foi implantada no Brasil em 1985. No entanto, a iniciativa já havia sido apresentada ainda na década de 1960. Do cadastro nacional de eleitores, previsto na Lei $\mathrm{n}^{-}$7.444/85, até a utilização das "máquinas de votar" na totalidade dos municípios brasileiros, em 2004, foi um longo percurso, apesar do curto espaço de tempo (NAZARENO et al., 2007). Em 1996 foi iniciada a primeira votação eletrônica do Brasil. $\mathrm{Na}$ época, 33\% do eleitorado votou nas urnas eletrônicas. Em 1998, esse percentual se elevou para $66 \%$ e finalmente, em 2004, a totalidade foi atingida. Convém mencionar que, em 2006, cerca de 125 milhões de pessoas exerceram seu direito de votar de forma eletrônica (TribunAL Superior Eleitoral, 2009).

A urna eletrônica é constituída do microterminal e do terminal do eleitor. No primeiro, o eleitor é identificado pelo número de seu título eleitoral; no segundo, o eleitor, de dentro de uma cabine específica, registra seu voto. O sistema e os dados estão protegidos por assinaturas digitais dos programas e pela criptografia dos dados. O acesso físico é resguardado por lacre de segurança. O primeiro evento ocorre antes do início da seção eleitoral com a impressão do relatório "zerésima" (listagem de todos os candidatos, com a finalidade de demonstrar a inexistência de votos nas urnas eletrônicas). No ato de votação, após a habilitação do eleitor, a urna mostra o cargo em disputa e aguarda a 
digitação do número do candidato. $\mathrm{Na}$ sequência, o número do candidato escolhido, com nome, fotografia e legenda, é apresentado para a confirmação do voto. A urna eletrônica apresenta a tela "fim" até que outro eleitor seja habilitado a votar (TSE, 2009).

O mecanismo consiste na utilização de um microcomputador, composto de memória; drive de disquete; módulo impressor; terminal do mesário ou microterminal; terminal do eleitor (composto de uma tela LCD e um teclado numérico através do qual o eleitor faz sua escolha: "branco", "corrige" e "confirma"). O sistema operacional utilizado em 2008 foi a plataforma Linux (software livre). A apresentação dos códigos-fonte está disponível para fiscalização por parte dos partidos políticos, Ministério Público e Ordem dos Advogados do Brasil (OAB) até 180 dias antes das eleições. Essa fiscalização, mediante análise das especificações, da documentação e do código-fonte, fazse com a utilização de duas ferramentas disponibilizadas pelo TSE: Understanding $C$ e Source Navigator. Por segurança, os sistemas eleitorais só funcionam nos computadores da justiça eleitoral, para que, se interceptados, não haja possibilidade de instalação dos arquivos em computadores externos (TSE, 2009).

O próximo passo do processo de aperfeiçoamento do voto eletrônico é a adoção de leitor biométrico para reconhecer o usuário (no caso, o eleitor). $\mathrm{Na}$ eleição de 2007, o mecanismo foi testado em três cidades, e o presidente do TSE declarou serem necessários $\mathrm{R} \$ 250$ milhões para modificar a urna eletrônica para as eleições de 2010. Com a mudança, a justiça eleitoral esperava ampliar o cadastro biométrico dos atuais 43 mil para 4 milhões de eleitores. $\mathrm{O}$ cadastro biométrico significaria mais um passo em direção ao aperfeiçoamento do processo eleitoral, evitando fraudes. Para isso, seria necessário construir 100 mil urnas eletrônicas biométricas em 2009, afirmou o presidente do Tribunal. (JoRnal Folha DE S. PAulo, 2009).

A iniciativa foi premiada em 2003, no 8 Concurso Inovação na Gestão Pública Federal, promovido pela ENAP, em função do esforço na logística de entrega e coleta das urnas eletrônicas em todo o território nacional, atividade promovida com base na parceria entre justiça eleitoral e ECT. Além da tecnologia empregada nas urnas, para distribuir 250 mil urnas eletrônicas em mais de 2.800 zonas e 335 mil seções eleitorais em mais de 5 mil municípios brasileiros, foram necessários cerca de 14 mil veículos (carros, motos, barcos, aviões) e quase 12 mil trabalhadores. A eficiência da eleição de 2002 pode ser medida pelo curto espaço de tempo decorrido entre o último voto e o encerramento da apuração, pouco mais de duas horas depois (Paiva e Araújo, 2003).

Segundo o TSE (2009), alguns países já realizaram eleições com urnas eletrônicas emprestadas pelo Brasil (Argentina, Equador, México, Paraguai e República Dominicana) e diversos outros já vieram visitar o TSE para conhecer o mecanismo (Alemanha, Colômbia, Estados Unidos, Índia, Moçambique e Turquia, entre outros).

Como todo e qualquer processo, a urna eletrônica não está isenta de críticas ou até mesmo descrença, característica típica de atividade que mobiliza milhões de pessoas, aspectos políticos e ideológicos. Parcela relevante das críticas foi superada em função da edição da Lei $\mathrm{n}^{\circ}$ 12.034, de 29 de setembro de 2009, que instituiu, entre outras questões, o voto impresso a partir das eleições de 2014. O mecanismo permitirá a conferência visual, a confirmação e a impressão, de forma 
automática, da escolha do eleitor, sem prejuízo dos avanços obtidos com a implantação do voto eletrônico.

\section{Considerações finais}

Tendo como panorama geral o surgimento e desenvolvimento da sociedade da informação, o presente trabalho teve como objetivo apresentar cinco experiências inovadoras na gestão pública brasileira, todas elas casos de sucesso no uso intensivo de tecnologia de informação e comunicação. De um modo geral, o que se observa é que a administração pública vem passando por um período de grandes mudanças, sendo que a maioria das transformações tem sido sustentada por um investimento pesado em tecnologia de informação e comunicação. Daí a tendência de diversos autores classificarem este movimento como "governo eletrônico".

Ainda que as experiências brasileiras narradas apontem para um cenário positivo, algumas ressalvas precisam ser apresentadas, até porque o tema "governo eletrônico" já ocupou espaço mais privilegiado na agenda nacional. Primeiramente, a despeito de existir uma política que cuida especificamente de padrões de interoperabilidade, vale assinalar que o poder público brasileiro ainda não foi capaz de promover a interação efetiva entre os diversos órgãos que compõem a administração pública e o compartilhamento de informações entre os três níveis de governo e destes dois conjuntos com a sociedade civil. Sendo esse passo essencial, não só para o governo eletrônico, mas também para propiciar maior eficiência ao serviço público.

Para efeito de ilustração, cabe mencionar a iniciativa portuguesa com a instituição do "Cartão do Cidadão", mecanismo que simplifica a vida dos cidadãos ao congregar em um mesmo instrumento diversos serviços (identidade, saúde pública, fisco, previdência, dentre outros). $\mathrm{O}$ mecanismo já é utilizado em outros países, tais como Áustria, Bélgica, Estônia, Finlândia, Suécia e Cingapura, conforme Portugal (2006b). No Brasil, merece registro a edição de Lei que trata da matéria, prevendo um único registro para documentos como carteira de identidade, o passaporte, o CPF e a carteira de motorista. A Lei 12.058, que autoriza o registro civil único, foi sancionada pelo presidente Luiz Inácio Lula da Silva em 13 de outubro de 2009 (FOLHA ON LINE, 2010).

A segunda questão, que destoa um pouco dos aspectos favoráveis mencionados quando da apresentação dos casos de sucesso, é a exclusão digital. Não obstante o esforço governamental nos seus diversos níveis, os números que quantificam os usuários de TICs - notadamente internet - indicam que o Brasil ainda tem muito a progredir, posto que o quadro de desigualdades existente na sociedade brasileira se repete no campo da tecnologia da informação. Portanto, novas políticas públicas mais eficazes no combate à exclusão digital precisam ser desenvolvidas, pois, do contrário, as inovações tecnológicas (inclusive algumas daquelas enumeradas neste artigo) podem ter seus resultados comprometidos, bem como podem ampliar ainda mais o fosso entre os incluídos e excluídos.

Assim, o que se espera é que o governo eletrônico contribua para o aprimoramento dos serviços públicos, e assim o país possa atingir níveis elevados de desenvolvimento humano, de modo a construir uma democracia sólida e igualitária.

(Artigo recebido em agosto de 2009. Versão final em maio de 2010) 


\section{Notas}

1 Em contrapartida, existem autores que fracionam ainda mais as etapas. Gruening (1998), por exemplo, discrimina pelo menos cinco etapas: a) Administração Pública Clássica; b) Administração Pública Neoclássica (quando após a II Guerra Mundial os princípios da fase anterior foram questionados, com destaque para a obra de Herbert Simon); c) Teoria da Escolha Pública (movimento fundado por Buchanan e Nutter, cujo objetivo principal foi se contrapor à intervenção do Estado na economia, preconizada pelo Welfare State. Outro importante aspecto foi identiticar o interesse pessoal na condução dos processos políticos e econômicos); d) Nova Administração Pública (movimento surgido nos anos 1960, nos Estados Unidos, contra a visão clássica, que criticava a discriminação, injustiça e iniquidade); e) Nova Gestão Pública.

2 Snellen (2002) compartilha da ideia de que a introdução de novas tecnologias de informação e de comunicações é o segundo grande movimento de reforma da administração pública.

3 Diniz et al. (2009) discrimina outros termos com o mesmo significado de governo eletrônico: e-gov, eletronic government, e-government, e-governo, wired-government, governo digital, governo virtual, Estado virtual, governança eletrônica.

4 Buzato (2009), após rever diversos conceitos e significados das palavras usuais ao tema, apresenta três concepções de inclusão digital: a) letramento e inclusão que resultou do processo de normalização, quantificação e graduação valorativa impostos pela escolarização sobre os letramentos sociais; b) apropriação crítica das TICs como forma de autoafirmação cultural e de conscientização e mobilização político-ideológica para a construção do socialismo; c) um processo criativo, aberto, conflituoso e dialógico pelo qual grupos subalternos se apropriam das TICs de forma não prescrita por outrem. O autor conclui que cabe aos educadores, aos formuladores e implementadores de políticas de inclusão compreender e fomentar os modos pelos quais os sujeitos podem usar as TICs para definir e implementar suas próprias demandas.

5 Dados disponíveis em www.portaldatransparencia.gov.br, consultado em 16 de maio de 2009.

6 A concepção do Portal foi inovadora; contudo, cabe mencionar que ainda em 1999 a Secretaria Federal de Controle Interno, na época unidade singular do Ministério da Fazenda, atualmente parte da própria CGU, inaugurou o processo de publicização dos gastos com a disponibilização em seu site da "Consulta Convênio", mecanismo por meio do qual os cidadãos acessavam os dados sobre as transferências via convênios (BALBE, 2006). A mencionada consulta foi incorporada ao Portal.

7 Segundo conta a Bíblia, Jesus teria nascido durante o deslocamento de José e Maria de Nazareth, na Galiléia até Belém, na Judéia, para responder ao Censo ordenado por Cesar Augusto.

882 mil Pocket PCs, 82 mil licenças de Windows Mobile 5.0 e SQL Server Mobile e, para recebimento das informações, o sistema de banco de dados Microsoft SQL Server Enterprise 2005, rodando em servidores equipados com Microsoft Windows Server 2003 R2 Enterprise e Standard. Informação extraída do texto "Mobilidade", consultado em download.microsoft.com/download/3/ 2/2/322D6BF7-9452-4F27-B3FE-1330C5C4A9DB/MatCapa_Case_IBGE.pdf.

9 Informação extraída do texto "Mobilidade", consultado em download.microsoft.com/ download/3/2/2/322D6BF7-9452-4F27-B3FE-1330C5C4A9DB/MatCapa_Case_IBGE.pdf

${ }_{10}$ Conforme consta no site www.certisign.com.br, o e-CPF, por exemplo, custa a partir de $\mathrm{R} \$ 110,00$. Trata-se de um serviço prestado por empresa privada, a qual é uma das três primeiras Autoridades Certificadoras do mundo a emitir certificados digitais e está credenciada para operar em múltiplas hierarquias, como ICP-Brasil, VeriSign Trust Network (VTN) e hierarquia privada. Em Portugal, conforme entrevista com responsável pela Loja do Cidadão em Ovidelas (Lisboa) em 29/ 04/2009, a leitora optica do Cartão do Cidadão custa 12 euros (aproximadamente R \$ 36). 


\section{Referências bibliográficas}

ABranson, M.; MEAns, G. E. E-government 2001 - IBM endowment for the business of government. Rowman \& Littlefield Publishers, 2001.

AssumpÇão, Rodrigo Ortiz D’Avila. Inclusão digital e governo eletrônico: esforços conjuntos para a redução das desigualdades. XIV Congreso Internacional del CLAD sobre la Reforma del Estado y de la Administración Pública, Salvador, 2009.

BalBe, Ronald da Silva. Uma longa história de corrupção: dos anões às sanguessugas. Revista da CGU, Ano I, no 1, 2006.

Barbosa, Alexandre et al. Os caminhos para o avanço do governo eletrônico no Brasil, In: Barbosa, Alexandre (Coord.) Pesquisa sobre o Uso das Tecnologias da Informação e Comunicação no Brasil. São Paulo: Comitê Gestor da Internet no Brasil, 2009.

Braga, Lamartine Vieira; Alves, Welington Souza; Figueiredo, Rejane Maria da Costa; Santos, Rildo Ribeiro dos. O papel do Governo Eletrônico no fortalecimento da governança do setor público. Revista do Serviço Público, 59(1), 2008.

Castelds, Manuel. A Sociedade em rede. In: Cardoso, Gustavo et. al. (2005), A Sociedade em Rede em Portugal. Porto: Campo das Letras, 2005. p. 19-29.

Castelds, Manuel; Himanen, Pekka. A Sociedade da Informação e o Estado-Providência: o Modelo Finlandês. Lisboa: Fundação Calouste Gulbenkian, 2002.

Controladoria-geral Da União. Portal da Transparência. Disponível em: www.cgu.gov.br. Acesso em 15 mai. 2009.

Denhardt, Robert B.; Denhardt, Janet V. The new public service: serving, not steering. New York: M.E.Sharpe, 2007.

Diniz, Eduardo. O governo eletrônico no Brasil: perspectiva histórica a partir de um modelo estruturado de análise. Revista de Administração Pública, 43(1): 23-48, 2009.

FolHa dE SÃo PAULO. TSE pede R $\$ 250$ milhões a Lula para modernizar urna eletrônica para 2010. Disponível em: http://www1.folha.uol.com.br/fsp/brasil/fc2003200906.htm. Acesso em: 19 mai. 2009.

FolHa on Line. Presidente Lula sanciona lei que unifica documentos. Disponível em: http:/ /www1.folha.uol.com.br/folha/cotidiano/ult95u638755.shtml. Acesso em 19 jan. 2010.

Fundo Nacional de Desenvolvimento da Educação. Programas de livros didáticos Disponível em: http://www.fnde.gov.br/home/index.jsp?arquivo=livro_didatico.html. Acesso em: 17 mai. 2009.

Giauque, David. New Public Management and Organizational Regulation: the liberal Bureaucracy. International Review of Administrative Sciences, 69: 4, 2003.

Giddens, Anthony. As consequências da modernidade. São Paulo: Editora Unesp, 1991.

Gil-García, José R.; LunA-Reyes, Luis F. A Brief Introduction to Eletronic Government: Definition, Applications and Stages. Revista de Administración Pública, Volumen XLIII, no 2 (mayo-agosto), Nueva Época, Cuajimalpa (México), 2008.

Grönlund, A.; Horan, T. Introducing E-Gov: history, definitions, and issues. Communications of AIS, Volume 15, 2005. 
Gruening, Gernod. Origin and theoretical basis of the New Public Management (NPM). Artigo apresentado no International Public Management Neywork, conferência em Salem/Oregon, 1998. Disponível em: www.inpuma.net/research/papers/salem/ gernod.doc . Acesso em: 15 mai. 2009.

instituto Brasileiro de Geografia e Estatística. História da Contagem da População. Disponível em http://censos2007.ibge.gov.br/hist_contagem.shtm. Acesso em: 17 mai. 2009. Internet World Stats. Disponível em: www.internetworldstats.com. Acesso em: 29 dez. 2009.

Kingdon, John. Juntando as coisas. In: Saravia, Enrique e Ferrarezi, Elisabete (Org.). Coletânea Políticas Públicas. Brasília: ENAP, 2006. v. 01 p. 21-42.

Mariano, Luiz F. P. Coleta de dados por computadores de mão para censos de proporções continentais. In: Ações premiadas no $12^{\circ}$ Concurso Inovação na Gestão Pública Federal. Brasília: ENAP, 2007.

Mattos, Fernando A. Mansor de; Chagas, Gleison José do Nascimento. Desafios da inclusão digital no Brasil. Perspectivas em Ciência da Informação, v.13, n.1, p.67-94, jan./abr. 2008.

Nascimento, Luciana S. Aspectos Operacionais para a Escolha do Livro Didático. Disponível em: http://www.fnde.gov.br/home/index.jsp?arquivo=livro_didatico.html. Acesso em: 17 mai. 2009.

NAZAREno, C. et. al, Tecnologias da Informação e sociedade: o panorama brasileiro. Brasília: Câmara dos Deputados, 2007.

Paiva, Andréa B.; Araújo, Frederico A. G. (org.). Ações premiadas no 8o Concurso Inovação na Gestão Pública Federal. Brasília: ENAP, 2004.

Portugal. Cartão de Cidadão. Disponível em: http://www.cartaodecidadao.pt/ index.php?option $=$ com_content\&task $=$ view \&id $=196 \&$ Itemid $=103 \&$ lang $=$ pt. Acesso: 25 mai. 2009.

Portugal. Relatório de melhores práticas mundiais. Unidade de Coordenação da Modernização Administrativa. Disponível em: http://www.umic.pt/index.php? option $=$ com_content $\&$ task $=$ view $\&$ id $=2699 \&$ Itemid $=117$. Acesso: 25 mai. 2009 .

Rosenbloom, David H. Public Administration. Understanding Management, Politics, and Law in the Public Sector. New York: McGraw-Hill, 1998.

Schwartz, Sonia. Os Programas do Livro - Panorama. Disponível em http:// www.fnde.gov.br/home/index.jsp?arquivo=livro_didatico.html. Acesso: 17 mai. 2009. Secretaria Da Receita Federal (2009a). Mais de 25 milhões de contribuintes já enviaram declaração de IR. Disponível em: http:/ / www.receita.fazenda.gov.br/AutomaticoSRFSinot/ 2009/04/30/2009_04_30_19_42_03_289906666.html, Acesso: 20 mai 2009.

Secretaria Da Receita Federal (2009b). 10 anos na internet. Disponível em: http:/ / www.receita.fazenda.gov.br/10anos/default.htm. Acesso: 20 mai. 2009.

Secretaria de Logística e Tecnologia da Informação (2009). Melhorias da Infraestrutura de TICs. Disponível em: http://www.planejamento.gov.br/ secretaria.asp?cat $=75 \&$ sub $=104 \& \mathrm{sec}=7$. Acesso: 31 mai. 2009 . 
Silva, Raimundo N. R. Logística de distribuição e entrega dos objetos do Programa Nacional do Livro Didático (PNLD). In: Coutinho, Gustavo Amorim (org.). Ações premiadas no 7ํ. Concurso Inovação na Gestão Pública Federal. Brasília: ENAP, 2002.

SNELLEN, Ignace. Electronic governance: implications for citizens, politicians and public servants. International Review of Administrative Sciences, Vol. 68, 183-198, 2002.

Tribunal Superior Eleitoral. Voto Eletrônico. Disponível em: http://www.tse.gov.br/ internet/eleicoes/votoeletronico/sumario.htm. Acesso: 18 mai. 2009.

Waiselfisz, Julio J. Mapa das desigualdades digitais no Brasil. Brasília: Rede de Informação Tecnológica Latino-Americana, RITLA, 2007. 


\section{Resumo-Resumen-Abstract}

\section{Uso de tecnologias de informação e comunicação na gestão pública: exemplos no governo federal}

Ronald da Silva Balbe

A administração pública passou por diversas mudanças nos últimos 30 anos. Parte dessas alterações tem origem nas oportunidades criadas pelas inovações tecnológicas. O objetivo deste trabalho é apresentar como tem sido o uso de tecnologias da informação e comunicação (TICs) nas inovações promovidas na administração pública federal brasileira. Para tanto, tomamos como base a descrição de cinco experiências inovadoras em TIC premiadas nos concursos anuais Inovação na Gestão Pública Federal, realizados pela Escola Nacional de Administração Pública (ENAP): o Portal da Transparência da Controladoria-Geral da União (CGU); o Programa Nacional do Livro Didático; o uso dos computadores de mão pelo Instituto Brasileiro de Geografia e Estatística (IBGE); a entrega da Declaração do Imposto de Renda via internet; e a utilização de urnas eletrônicas nas eleições brasileiras. A despeito da relevância dos avanços do governo eletrônico brasileiro até aqui, medidas de aprimoramento da interação entre os diversos órgãos públicos e também das políticas públicas de inclusão digital ainda se fazem necessárias.

Palavras-chave: Governo eletrônico, inovação na gestão pública, tecnologia da informação e comunicação

\section{Uso de tecnologías de información y comunicación en la gestión pública: experiencias en el gobierno federal \\ Ronald da Silva Balbe}

La administración pública ha experimentado diversos cambios en los últimos 30 años. Algunos de estos cambios se basan en las oportunidades creadas por las innovaciones tecnológicas. El objetivo de este trabajo es presentar las últimas innovaciones en Tecnologías de Información y Comunicación en el gobierno federal brasileño. Por lo tanto, se describen cinco experiencias innovadoras en las TIC galardonadas en el concurso anual "Innovación en la Gestión Pública Federal”, realizado por la Escuela Nacional de Administración Pública (ENAP): Portal de la Transparencia de la Contraloría General de la Unión (CGU); el Programa Nacional del Libro Didáctico (PNLD), la utilización de ordenadores portátiles por el Instituto Brasileño de Geografía y Estadística (IBGE); la entrega de la declaración del Impuesto sobre la Renta a través de Internet; y el uso de urnas electrónicas en las elecciones brasileñas. A pesar de los relevantes avances del gobierno electrónico brasileño (e-gov), medidas de perfeccionamiento de la interacción entre los diversos organismos públicos y de las políticas públicas de inclusión digital son todavía necesarias.

Palabras clave: Gobierno electrónico, innovación en la gestión pública, tecnologías de información y comunicación

\section{Information and communication technologies: cases in federal government}

Ronald da Silva Balbe

Public Administration has undergone several changes in the last 30 years. Some of these changes are rooted in the opportunities created by technological innovations. The objective of this work is to present the latest innovations in Information and Communication Technology within the Brazilian federal government. To this end, we describe five innovative experiences in ICT awarded 
the annual "Innovation in Federal Public Management", conducted by the National School of Public Administration: the Transparency Portal of Office of Comptroller General, the National Program of Textbooks (PNLD), the use of computers in hand by the Brazilian Institute of Geography and Statistics (IBGE), the delivery of the Statement of Income Tax via the Internet, and use of electronic polls in Brazilian elections. Despite the advances of the Brazilian e-government being relevant, measures to improve the interaction between the various public agencies and public policies of digital inclusion are still necessary.

Keywords: E-government, innovation in public management, information and communication technology

Ronald da Silva Balbe

Administrador e economista, mestrando em Administração Pública pelo Instituto Universitário de Lisboa (Portugal) e analista de Finanças e Controle em exercício na Secretaria Federal de Controle Interno (SFC/CGU) desde 1996. Contato: ronald.balbe@gmail.com 


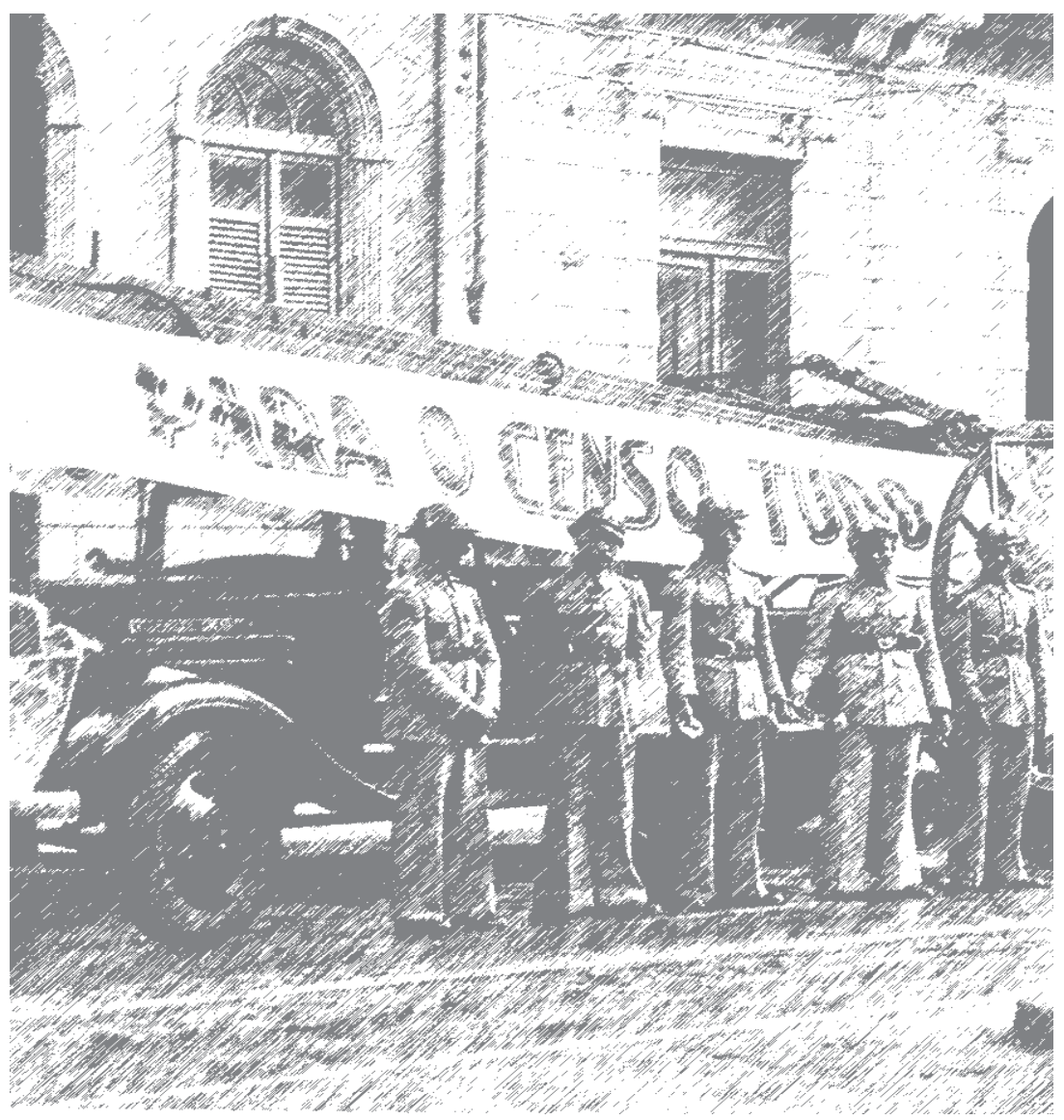

